\title{
PENGAMBILAN TEMBAGA DARI BATUAN BORNIT (Cu5FeS4) VARIASI RAPAT ARUS DAN PENGOMPLEKS EDTA SECARA ELEKTROKIMIA
}

\author{
Abdul Haris, Didik Setiyo Widodo dan Lina Yuanita \\ Laboratorium Kimia Analitik Jurusan Kimia Laboratorium Kimia Analitik Jurusan Kimia Fakultas \\ MIPA Universitas Diponegoro Semarang 50275
}

\begin{abstract}
ABSTRAK
Telah dilakukan penelitian tentang pemisahan tembaga dari mineral bornit terhadap pengaruh rapat arus dan pengompleks EDTA secara elektrolisis. Serbuk bornit dilarutkan dalam besi(III) sulfat dan diendapkan dengan variasi rapat arus menggunakan elektrode karbon selama 1 jam.

Dari hasil penelitian diperoleh kadar tembaga maksimal yang terlarut sebesar 14,88\% pada konsentrasi besi(III) sulfat 0,6 M. Semakin besar rapat arus yang digunakan pada elektrolisis, kuantitas endapan semakin meningkat dan endapan tembaga maksimal 1,69 mg terbentuk pada penambahan pengompleks EDTA 0,20 M dan rapat arus 0,05 A/cm2. Keberadaan pengompleks EDTA mampu menurunkan potensial yang diperlukan sehingga meningkatkan kemurnian dan kekuatan pelapisan tembaga. Kemurnian endapan tembaga tertinggi didapatkan pada elektrolisis dengan penambahan pengompleks EDTA 0,20 M sebesar 93,88\%
\end{abstract}

\section{Kata kunci:bornit, tembaga, rapat arus, pengompleks EDTA}

\section{PENDAHULUAN}

Bornit $\left(\mathrm{Cu}_{5} \mathrm{FeS}_{4}\right)$ merupakan mineral tembaga sulfida dengan komposisi tembaga 50-70\% dan besi $6,5-15 \%$ (Ford, 2005). Salah satu metode sederhana dalam pengendapan logam dari mineral batuan adalah elektrolisis. Kelebihan dari metode elektrolisis antara lain: prosesnya cepat, peralatan lebih sederhana dan kemurnian endapan cukup besar, dan kemurnian logam hasil elektrolisis dapat mencapai 99,9\% (Cottrel, 1975).

Tembaga mempunyai nilai ekonomis tinggi karena kegunaannya yang relatif luas. Ekplorasi tembaga dari mineral bornit telah banyak dilakukan tetapi belum diperoleh hasil yang maksimal, sehingga perlu dilakukan optimasi keadaan mengenai pengaruh rapat arus dan peran pengompleks terhadap kuantitas dan kualitas pengendapan. Pelarutan tembaga dari bornit merupakan tahapan penting dalam pengambilan tembaga dari batuan. Miskufova, dkk (2004) melakukan pelarutan tembaga dari mineral kalkopirit dalam pelarut besi (III) sulfat. Pengambilan logam tembaga dengan metode elektrolisis tanpa penambahan agen pengompleks didapatkan endapan yang rapuh, sedangkan elektrolisis dengan penambahan pengompleks memberikan hasil endapan yang lebih kuat dibandingkan elektrolisis tanpa penambahan pengompleks. Etilendiamina tetra asetat (EDTA) merupakan ligan polidentat, yaitu ligan yang mempunyai dua atau lebih atom donor yang secara bersamaan dapat mengikat sebuah ion logam. EDTA merupakan anion yang mempunyai enam atom donor yang dapat digunakan untuk mengikat sebuah atom logam dan untuk membentuk kompleks yang stabil dengan membungkus dirinya di sekeliling ion logam tersebut.

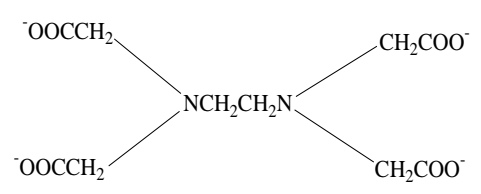

Gambar 1. Struktur EDTA 
Pengompleks berfungsi untuk membentuk kompleks dengan kation yang akan diendapkan pada katoda. Semakin tinggi nilai tetapan kestabilan kompleks maka senyawa kompleks yang terbentuk semakin stabil. Secara kuantitatif tetapan kestabilan ion kompleks $[\mathrm{Cu}(\mathrm{EDTA})]^{2-}$ sebesar 6,3 x $10^{18}$ adalah ion kompleks yang stabil (Brady, 1994). Dengan membentuk kompleks, logam-logam akan mempunyai kelarutan yang lebih besar dibandingkan dengan bentuk garamnya (Svehla, 1990), sehingga dengan diberikan beda potensial pada kedua elektroda dari sel elektrolisis, logam tembaga dapat dengan mudah bergerak dan mengendap di katoda (Svehla, 1990).

Berdasarkan latar belakang tersebut, maka dalam penelitian ini dilakukan pelarutan tembaga dari batuan bornit dengan pelarut besi (III) sulfat dan pengendapan tembaga dari batuan bornit secara elektrolisis dengan variasi rapat arus dan penambahan pengompleks EDTA. Dengan mengetahui pengaruh rapat arus dan pengompleks terhadap pengendapan tembaga secara elektrolisis, diharapkan dapat memberikan produk endapan tembaga dengan kualitas dan kuantitas maksimal.

\section{METODOLOGI}

\section{Alat dan Bahan}

Alat: elektroanaliser, spektrofotometer serapan atom, pemanas listrik, pengaduk magnetik, elektroda karbon (grafit), alat-alat gelas.

Bahan: batuan bornit, larutan besi (III) sulfat, larutan asam nitrat 65\%, pengompleks etilendiamina tetra asetat dan akuades.
Prosedur Kerja

Penanganan Sampel: Batuan bornit dihancurkan menjadi serbuk dengan ukuran 200 mesh dan diaktivasi pada suhu $450^{\circ} \mathrm{C}$ selama 1 jam.

Pelarutan Serbuk Bornit: Serbuk tembaga hasil aktivasi dilarutkan dalam pelarut besi (III) sulfat dengan variasi konsentrasi $0,12 \mathrm{M} ; 0,48$ M; 0,6 M; 0,8 M; 1,0 M; 1,2 M; 1,4 M. Pelarutan dilakukan selama 3 jam pada suhu kamar. Pengukuran konsentrasi tembaga terlarut dari batuan bornit menggunakan AAS.

\section{Pengendapan $\mathrm{Cu}^{2+}$ tanpa Penambahan Pengompleks:}

Sebanyak $50 \mathrm{ml}$ larutan dari batuan bornit dengan konsentrasi tembaga maksimal dielektrolisis menggunakan elektroda karbon. Elektrolisis untuk pengendapan tembaga tanpa penambahan pengompleks dilakukan pada rapat arus tetap $0,0005 \mathrm{~A} / \mathrm{cm}^{2}$ selama 1 jam. Elektrolisis dilakukan juga pada rapat arus 0,0010; 0,0050; 0,0100; $0,0500 \quad \mathrm{~A} / \mathrm{cm}^{2}$. Kuantitas endapan pada katoda ditentukan dengan penimbangan.

\section{Pengendapan $\mathrm{Cu}^{2+}$ Dengan Penambahan Pengompleks EDTA:}

Sebanyak $50 \mathrm{ml}$ larutan dari hasil pelarutan batuan bornit dengan konsentrasi tembaga terlarut maksimal kemudian dielektrolisis menggunakan elektroda karbon. Elektrolisis untuk pengendapan tembaga dengan penambahan pengompleks EDTA dilakukan pada rapat arus tetap $0,0005 \mathrm{~A} / \mathrm{cm}^{2}$ selama $1 \mathrm{jam}$. EDTA yang ditambahkan sebanyak $7 \mathrm{ml} \mathrm{0,20} \mathrm{M}$. Elektrolisis dengan penambahan pengompleks dilakukan juga pada rapat arus 0,0010; 0,0050; 
0,0100; 0,0500 A/cm². Kuantitas endapan pada katoda ditentukan dengan penimbangan.

\section{HASIL DAN PEMBAHASAN}

\section{Penanganan Sampel dan Pelarutan Tembaga}

Sampel bornit dibuat menjadi serbuk berukuran 200 mesh agar luas permukaannya semakin besar. Serbuk bornit diaktivasi pada suhu $450{ }^{\circ} \mathrm{C}$ untuk melemahkan ikatan komponen unsur/logam yang terdapat dalam batuan.

Besi(III) sulfat mempunyai potensial redoks yang tinggi sehingga mampu melarutkan serbuk bornit. Pelarutan berlangsung spontan pada temperatur kamar karena energi bebas Gibbs reaksi bernilai negatif (Miskufova dkk, 2004).

$\mathrm{Cu}_{5} \mathrm{FeS}_{4}(\mathrm{~s})+6 \mathrm{Fe}_{2}\left(\mathrm{SO}_{4}\right)_{3}(\mathrm{aq}) \rightleftharpoons 5 \mathrm{CuSO}_{4}$ $(\mathrm{aq})+13 \mathrm{FeSO}_{4}(\mathrm{aq})+4 \mathrm{~S}(\mathrm{aq})$

Pelarutan serbuk bornit menggunakan pelarut besi (III) sulfat (dengan variasi konsentrasi) menghasilkan nilai tembaga terlarut yang berbeda-beda dapat dilihat pada gambar 2 .

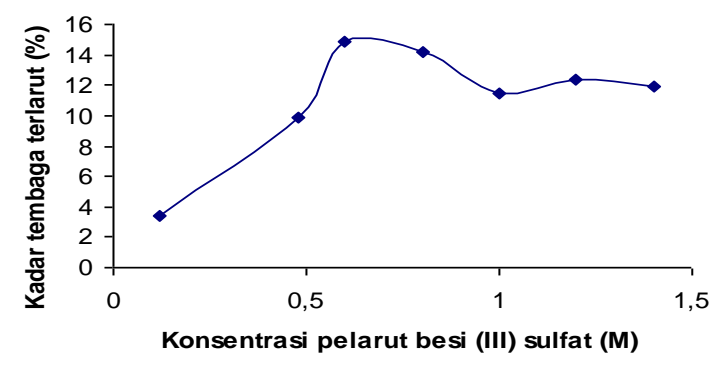

Gambar 2. Kadar tembaga terlarut terhadap konsentrasi pelarut besi (III) sulfat

Pelarutan serbuk bornit menggunakan pelarut besi (III) sulfat pada suhu kamar menghasilkan tembaga terlarut maksimal sebesar $14,88 \%$ dengan konsentrasi pelarut besi(III) sulfat sebesar $0,60 \mathrm{M}$.
Pengendapan tembaga secara elektrolisis dilakukan tanpa penambahan pengompleks dan dengan penambahan pengompleks EDTA 0,20 $\mathrm{M}$ pada variasi rapat arus. Tabel 1. menunjukkan kuantitas endapan tembaga pada variasi rapat arus yang diperoleh dari elektrolisis tanpa penambahan pengompleks dan penambahan pengompleks. Pengendapan tembaga secara elektrolisis tanpa penambahan pengompleks menghasilkan kuantitas endapan tembaga maksimal 1,91 mg pada rapat arus $0,01 \mathrm{~A} / \mathrm{cm}^{2}$. Elektrolisis dengan penambahan pengompleks EDTA 0,20 M menghasilkan kuantitas endapan tembaga maksimal 1,69 $\mathrm{mg}$ pada rapat arus 0,05 $\mathrm{A} / \mathrm{cm}^{2}$.

Tabel 1. Kuantitas endapan tembaga hasil elektrolisis (variasi rapat arus) tanpa penambahan pengompleks dan dengan penambahan pengompleks EDTA 0,20 $\mathrm{M}$

\begin{tabular}{|c|c|c|c|}
\hline \multirow[b]{2}{*}{ No } & \multirow[b]{2}{*}{$\begin{array}{c}\text { Rapat } \\
\text { Arus } \\
\left(\mathrm{A} / \mathrm{cm}^{2}\right. \\
\quad)\end{array}$} & \multicolumn{2}{|c|}{ Kuantitas endapan $\mathrm{Cu}(\mathrm{mg})$} \\
\hline & & $\begin{array}{c}\text { Tanpa } \\
\text { pengomplek } \\
\text { s EDTA }\end{array}$ & $\begin{array}{c}\text { Dengan } \\
\text { Pengomplek } \\
\text { s EDTA } 0,20 \\
\text { M }\end{array}$ \\
\hline 1. & 0,0005 & 0,16 & 0,00 \\
\hline 2. & 0,0010 & 1,46 & 0,92 \\
\hline 3. & 0,0050 & 1,39 & 0,64 \\
\hline 4. & 0,0100 & 1,91 & 0,98 \\
\hline 5. & 0,0500 & 0,77 & 1,69 \\
\hline
\end{tabular}

Berdasarkan tabel 1 elektrolisis tanpa penambahan pengompleks, semakin besar rapat arus yang digunakan meningkatkan kuantitas endapan dan pada penelitian ini diperoleh kuantitas endapan kembali menurun pada rapat arus tertentu. Elektrolisis dengan penambahan pengompleks memenuhi Hukum Faraday I, yaitu besar rapat arus yang digunakan semakin meningkatkan kuantitas endapan (Sukardjo, 1997). 
Elektrolisis tanpa penambahan pengompleks menggunakan listrik yang mengalir melalui larutan tidak hanya dimanfaatkan dalam pengendapan tembaga melainkan juga dimanfaatkan oleh reaksi lain yang menyertai, seperti pembentukan gas hidrogen dan oksigen. Hal ini mengakibatkan kuantitas tembaga yang dihasilkan sedikit. Adanya pengompleks mampu mengurangi pembentukan gelembunggelembung gas sehingga kuantitas endapan yang dihasilkan semakin tinggi.

Perbandingan kuantitas endapan secara praktek dan secara teoritis menghasilkan efisiensi arus. Efisiensi arus yang diperoleh pada elektrolisis tanpa penambahan pengompleks dan dengan penambahan pengompleks dapat dilihat pada gambar 3. Semakin besar rapat arus, efisiensi arus semakin kecil. Kesempatan ion tembaga untuk mengendap pada rapat arus yang kecil lebih besar jika dibandingkan dengan air karena potensial reduksi tembaga lebih tinggi. Hal inilah yang menyebabkan efisiensi arus menjadi tinggi pada rapat arus kecil.

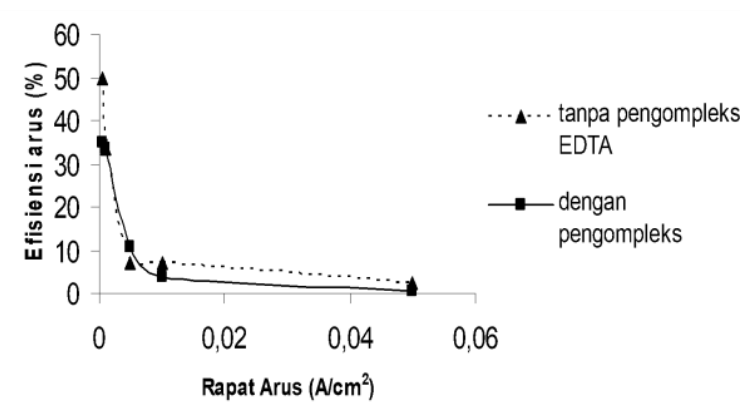

Gambar 3. Pengaruh rapat arus terhadap efisiensi arus elektrolisis tanpa pengompleks dan dengan pengompleks EDTA 0,20 M

Perbandingan kuantitas endapan hasil pengukuran dengan AAS dan penimbangan diperoleh kemurnian endapan seperti yang terlihat pada gambar 4. Kemurnian endapan ditentukan oleh komposisi endapan. Nilai kemurnian yang tinggi menunjukkan bahwa endapan yang diperoleh hanya mengandung sedikit pengotor dan nilai kemurnian yang rendah menunjukkan banyaknya pengotor yang ikut mengendap. Kemurnian tertinggi $73 \%$ pada rapat arus $0,001 \mathrm{~A} / \mathrm{cm}^{2}$ untuk elektrolisis tanpa penambahan pengompleks. Kemurnian tertinggi pada elektrolisis dengan penambahan pengompleks sebesar $93,88 \%$ pada rapat arus $0,05 \mathrm{~A} / \mathrm{cm}^{2}$.

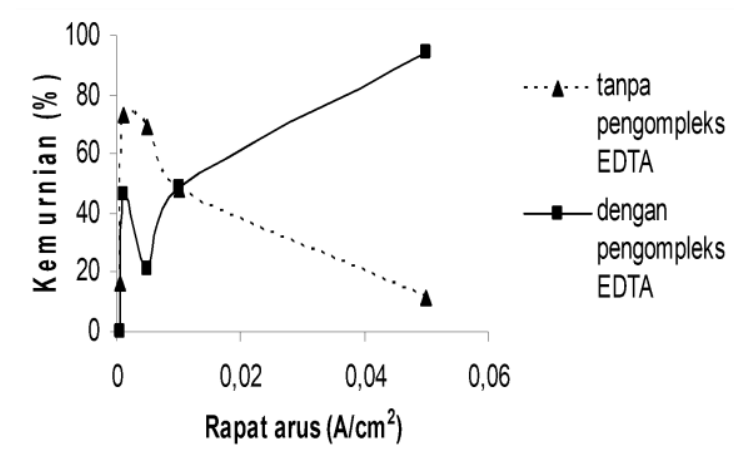

Gambar 4. Pengaruh rapat arus terhadap kemurnian endapan tembaga tanpa pengompleks dan dengan pengompleks EDTA 0,20 M

Hasil elektrolisis berupa endapan dan gas. Kemurnian endapan nilainya tidak dapat mencapai $100 \%$ karena adanya pengotor di dalam larutan. Pengotor dengan potensial di bawah tembaga ikut mengendap bersama tembaga. Gas yang dihasilkan selama reaksi berlangsung, mengganggu jalannya reaksi pada katoda dan anoda itu sendiri. Gas hidrogen menghalangi tembaga yang akan mengendap di katoda sehingga endapan yang dihasilkan menjadi rapuh dan tidak merata. Hal ini dapat diatasi dengan penambahan pengompleks, yaitu EDTA 0,20 M. Pengompleks mampu mengurangi pembentukan gas pada reaksi elektrolisis sehingga reaksi dapat berlangsung optimal. 
Pengaruh Pengompleks Terhadap Kualitas

\section{Pelapisan}

Pengaruh pengompleks pada proses elektrolisis adalah menurunkan potensial sel. Overpotensial dapat ditekan sehingga terbentuknya gas hidrogen dan oksigen menjadi berkurang. Penurunan potensial sel dapat diketahui dari reaksi yang terjadi pada elektrolisis dan persamaan Nernst.

Reaksi yang terjadi pada elektrolisis tanpa penambahan pengompleks adalah:

Katoda (C): $\mathrm{Cu}^{2+}{ }_{\text {aq }}+2 \mathrm{e} \longrightarrow \mathrm{Cu}_{(\mathrm{s})} \quad \mathrm{E}^{\mathrm{o}}=+0,340 \mathrm{~V}$

Anoda (C): $2 \mathrm{H}_{2} \mathrm{O} \rightarrow \mathrm{O}_{2}+4 \mathrm{H}^{+}{ }_{(\text {aq })}+4 \mathrm{e} \mathrm{E}^{\mathrm{o}}=-1,230 \mathrm{~V}$

$\mathrm{Cu}^{2+}{ }_{(\mathrm{aq})}+2 \mathrm{H}_{2} \mathrm{O} \rightarrow \mathrm{Cu}_{(\mathrm{s})}+\mathrm{O}_{2(\mathrm{~g})}+4 \mathrm{H}^{+}(\mathrm{aq}) \quad \mathrm{E}^{\mathrm{o}}=-0,890 \mathrm{~V}$

Reaksi yang terjadi pada elektrolisis tembaga dengan penambahan pengompleks EDTA adalah:

Kat: $[\mathrm{Cu}(\mathrm{EDTA})]^{2-}{ }_{\text {(aq })}+2 \mathrm{e} \rightarrow \mathrm{Cu}_{(\mathrm{s})}+(\mathrm{EDTA})^{4-} \mathrm{E}^{\mathrm{o}}=+0,895 \mathrm{~V}$

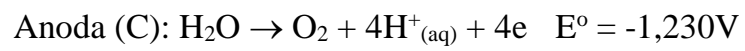

$\mathrm{Cu}^{2+}{ }_{(\mathrm{aq})}+\mathrm{H}_{2} \mathrm{O} \rightarrow \mathrm{Cu}_{(\mathrm{s})}+(\text { EDTA })^{4-}+\mathrm{O}_{2(\mathrm{~g})}+4 \mathrm{H}^{+}{ }_{(\mathrm{aq})} \mathrm{E}^{\mathrm{o}}=-0,335 \mathrm{~V}$

Berdasarkan reaksi yang terjadi pada elektrolisis, perbedaan nilai potensial elektroda untuk setengah reaksi terdapat di katoda. Nilai potensial katoda sangat menentukan harga potensial sel. Elektrolisis tanpa penambahan pengompleks mempunyai nilai potensial katoda sebesar $+0,340$ volt, sedangkan nilai potensial katoda untuk elektrolisis dengan penambahan pengompleks EDTA 0,20 M sebesar + 0,895volt.

Nilai potensial katoda dengan pengompleks apabila dibandingkan dengan nilai potensial katoda tanpa pengompleks, menjadi lebih tinggi dan menunjukkan bahwa kemampuan reduksi ion tembaga dengan adanya pengompleks menjadi lebih besar. Hal ini berpengaruh pada harga potensial sel. Keberadaan pengompleks akan menurunkan potensial sel yang diperlukan untuk mengendapkan logam tembaga. Potensial sel minimal yang diperlukan untuk pengendapan tembaga tanpa pengompleks sebesar 0,890 volt turun menjadi 0,335 volt dengan adanya pengompleks EDTA. Proses pengendapan tembaga dengan pengompleks menjadi lebih mudah berlangsung karena potensial yang diperlukan lebih rendah daripada tanpa pengompleks. Selain itu, adanya pengompleks menyebabkan kualitas endapan menjadi lebih baik. Hal ini dapat dilihat pada tabel berikut.

Tabel 1. Kekuatan tembaga hasil elektrolisis tanpa pengompleks dan dengan pengompleks EDTA 0,20 M

\begin{tabular}{|c|c|c|c|}
\hline \multirow{2}{*}{ No } & \multirow{2}{*}{$\begin{array}{c}\text { Rapat } \\
\text { Arus } \\
\left(\mathrm{A} / \mathrm{cm}^{2}\right. \\
\end{array}$} & \multicolumn{2}{|c|}{$\begin{array}{c}\text { Waktu Pelarutan (detik) } \\
\text { dalam } \mathrm{HNO}_{3} 3 \mathrm{M}\end{array}$} \\
\cline { 3 - 4 } & $\begin{array}{c}\text { Tanpa } \\
\text { pengomplek } \\
\text { s EDTA }\end{array}$ & $\begin{array}{c}\text { Dengan } \\
\text { Pengomplek } \\
\text { s EDTA } \\
0,20 \mathrm{M}\end{array}$ \\
\hline 1. & 0,0005 & 2 & 528 \\
\hline 2. & 0,0010 & 184 & 539 \\
\hline 3. & 0,0050 & 64 & 489 \\
\hline 4. & 0,0100 & 65 & 186 \\
\hline 5. & 0,0500 & 76 & 133 \\
\hline
\end{tabular}

Dari tabel di atas terlihat bahwa dengan adanya pengompleks mampu meningkatkan kualitas pelapisan endapan yang ditunjukkan oleh makin lamanya waktu pelarutan. Keberadaan pengompleks mampu mengurangi pembentukan gas hidrogen sehingga endapan yang dihasilkan semakin kuat dan merata. Kekuatan endapan tembaga dapat diketahui dengan pelarutan endapan dalam asam nitrat $3 \mathrm{M}$. Semakin lama pelarutan menunjukkan bahwa kekuatan tembaga semakin tinggi/tidak rapuh. Kekuatan endapan terbaik diperoleh pada rapat arus 0,001 
$\mathrm{A} / \mathrm{cm}^{2}$. Pada rapat arus tersebut endapan hasil elektrolisis tanpa penambahan pengompleks melarut selama 184 detik dan untuk endapan hasil elektrolisis dengan penambahan pengompleks melarut selama 539 detik. Endapan hasil elektrolisis dengan penambahan pengompleks lebih kuat dibandingkan endapan hasil elektrolisis tanpa pengompleks.

\section{UCAPAN TERIMAKASIH}

Terima kasih disampaikan kepada F MIPA UNDIP atas dana DIPA FMIPA Universitas Diponegoro yang telah membeayai penelitian ini.

\section{DAFTAR PUSTAKA}

Brown, T. L., 1997, Chemistry The Central Science, Prentice Hall, Inc., New Jersey.

Cottrell, A., 1975, An Introduction to Metallurgy, $2^{\text {nd }}$ Edition, Edward Arnold Ltd., London.

Ford, W. E., 2005, Dana's Textbook of Mineralogy With an Extended Treatise on Crystallography and Physical Mineralogy, Statish Kumar Jain, New Delhi.

Miskufova, Kuchar, Havlik, 2004, Leaching of Thermally Sulphidized Medium, Acta Metalurgica Slovaca.

Rieger, P. H., 1994, Electrochemistry, Champman and Hall, New York, 5-6, 398-400, 575-590. 